\title{
Differential effects of larval and adult nutrition on female survival, fecundity, and size of the yellow fever mosquito, Aedes aegypti
}

Jiayue Yan $^{*}$ (D), Roumaissa Kibech and Chris M. Stone

\begin{abstract}
Background: The yellow fever mosquito, Aedes aegypti, is the principal vector of medically-important infectious viruses that cause severe illness such as dengue fever, yellow fever and Zika. The transmission potential of mosquitoes for these arboviruses is largely shaped by their life history traits, such as size, survival and fecundity. These life history traits, to some degree, depend on environmental conditions, such as larval and adult nutrition (e.g., nectar availability). Both these types of nutrition are known to affect the energetic reserves and life history traits of adults, but whether and how nutrition obtained during larval and adult stages have an interactive influence on mosquito life history traits remains largely unknown.

Results: Here, we experimentally manipulated mosquito diets to create two nutritional levels at larval and adult stages, that is, a high or low amount of larval food (HL or LL) during larval stage, and a good and poor adult food (GA or PA, represents normal or weak concentration of sucrose) during adult stage. We then compared the size, survival and fecundity of female mosquitoes reared from these nutritional regimes. We found that larval and adult nutrition affected size and survival, respectively, without interactions, while both larval and adult nutrition influenced fecundity. There was a positive relationship between fecundity and size. In addition, this positive relationship was not affected by nutrition.

Conclusions: These findings highlight how larval and adult nutrition differentially influence female mosquito life history traits, suggesting that studies evaluating nutritional effects on vectorial capacity traits should account for environmental variation across life stages.
\end{abstract}

Keywords: Nutritional stress, Mosquito longevity, Survival curves, Egg number, Wing length, Hazard ratios

\section{Background}

The yellow fever mosquito (Diptera: Culicidae), Aedes aegypti (Linnaeus, 1762), is the principal vector of several arthropod-borne viruses (i.e., arboviruses) such as dengue, yellow fever, chikungunya and Zika, which continue to impose a heavy burden on public health globally

\footnotetext{
* Correspondence: jiayue@illinois.edu

Illinois Natural History Survey, University of Illinois at Urbana-Champaign, 1816 S. Oak St, Champaign, IL 61820, USA
}

[1-5]. Dengue virus (DENV), for example, is estimated to cause 390 million cases of human infection each year, 96 million of which have clinical manifestations [6]. These arboviruses have been re-emerging in many regions and expanding their ranges across the globe, partly due to urbanization and subsequent expansion of the distribution of Ae. aegypti [7]. Given their medical importance, the vectorial capacity of mosquitoes has been an important focus of study $[8,9]$. Vectorial capacity is

(c) The Author(s). 2021 Open Access This article is licensed under a Creative Commons Attribution 4.0 International License, which permits use, sharing, adaptation, distribution and reproduction in any medium or format, as long as you give appropriate credit to the original author(s) and the source, provide a link to the Creative Commons licence, and indicate if changes were made. The images or other third party material in this article are included in the article's Creative Commons licence, unless indicated otherwise in a credit line to the material. If material is not included in the article's Creative Commons licence and your intended use is not permitted by statutory regulation or exceeds the permitted use, you will need to obtain permission directly from the copyright holder. To view a copy of this licence, visit http://creativecommons.org/licenses/by/4.0/. The Creative Commons Public Domain Dedication waiver (http://creativecommons.org/publicdomain/zero/1.0/) applies to the data made available in this article, unless otherwise stated in a credit line to the data. 
simply an equation that isolates the entomological parameters from the basic reproduction number of a vector-borne disease (e.g., malaria [10]), often focusing on those parameters that can be measured under field conditions. It is a tremendously useful measure of transmission potential, which can guide implementation of control measures and increase our understanding of risk. Yet understanding the causes of variation in transmission potential between areas requires in-depth knowledge of the vector traits that influence vectorial capacity in a single locality. Mosquito life history traits, such as body size, survival and fecundity, can directly or indirectly influence mosquito population dynamics and vectorial capacity. For example, Alto et al [11] found that smaller-sized Ae. aegypti females were more susceptible to DENV infection and more likely to disseminate it than their larger counterparts. Longevity is a key competent of vectorial capacity as vectors must survive long enough to allow pathogens to replicate to a high level before the virus can be disseminated in subsequent bites [12]. Longevity and fecundity additionally affect the lifetime reproductive output of mosquitoes, and thereby influence local mosquito abundance, which also features as a parameter in the vectorial capacity equation. Despite the importance of life history traits, however, relatively few studies have examined how these traits can be influenced by the different environments experienced by mosquitoes across their developmental stages.

As an organism with a complex life cycle, mosquitoes experience highly distinct habitats from larval to adult stages and environmental factors may play a critical role in their fitness and performance [13]. The environment experienced by larvae may affect adult phenotypes through so called "carry-over effects" [14, 15]. For example, larval competition, food quantity and temperature have been reported to affect adult survival, size, longevity and vector competence [16-20]. At the same time, the environment experienced by adults, such as food quality/availability, or air temperature and the level of humidity, can also directly affect their life history traits and vector competence [21, 22]. Nonetheless, how environmental factors in both larval and adult stages may interactively affect life history traits or various aspects of mosquito behavior remains largely unknown (but see [23] for the influence of both larval and adult nutrition on mosquito biting persistence).

Nutrition is one of the environmental factors that affects all mosquito life history traits as it fuels development, growth, and performance. During the larval stage, microorganisms and particulate organic detritus are major nutritional resources and their abundance is readily affected by environmental changes, such as rainfall, competition, and predators of larvae [24]. As a container breeder, larval populations of Ae. aegypti can be regulated by nutritional stress derived from food limitation in the aquatic habitat [25]. After emergence, adult Ae. aegypti start foraging for food from terrestrial habitats nearby. Most mosquito species rely on plant sugars as an energy supply, while female mosquitoes require vertebrate blood as a nutritional resource for egg production. Previous studies suggested that female Ae. aegypti rarely feed on sugar [26] and that feeding on human blood alone may provide them with a fitness advantage $[27,28]$. However, sugar-feeding by female $A e$. aegypti may not be as unusual as thought previously, as support for frequent sugar-feeding in certain environments has been reported [29-31], and this propensity has been used to design attractive toxic sugar baits for Ae. aegypti control $[32,33]$. Like larvae, adults may also be influenced by nutritional stress derived from changes in food quality (e.g., sugar concentration [34]). Both larval and adult nutritional stress has been shown to associate with adult survival, reproduction, and growth [35]. However, little is known about whether and how larval nutritional stress influences the effects of adult nutrition on life history traits.

Here we experimentally examined the potential interactive effects of larval (quantity) and adult (sucrose concentration) nutrition on survival and fecundity of adult female Ae. aegypti. To do that, we set up cohorts with two amounts of food during larval stages and two concentrations of sucrose solution during the adult stage and compared life history traits between different levels of nutritional treatments.

\section{Methods}

\section{Mosquito rearing and treatments}

All mosquitoes were cultured using the $\mathrm{F}_{19}$ generation of an Ae. aegpyti colony established from eggs collected in Key West, FL. Eggs were hatched overnight in an enamel pan $(35 \times 25 \times 6 \mathrm{~cm})$ filled with $500 \mathrm{~mL}$ of deionized (DI) water and $2 \mathrm{~g}$ of brain heart infusion (Difco Laboratories, Detroit, USA). To minimize potential effects of variation in larval density on mosquito fitness and performance [36], first-instar larvae were randomly counted and 100 of them were placed in each enamel pan filled with $500 \mathrm{~mL}$ of DI water. The larvae were reared under two nutritional regimes, following Joy et al [35] and Telang et al [37]: a well-nourished treatment where $100 \mathrm{mg}$ of rabbit chow: lactalbumin: yeast (1:1:1) diet (Sigma-Aldrich, St. Louis, USA) was provided on days 2, 4, 5 and 6 post-hatching, representing high larval nutrition (hereafter $\mathrm{HL}$ ); or a malnourished treatment where $100 \mathrm{mg}$ of the same diet was provided only on days 2 and 6 post hatching, representing low larval nutrition (hereafter LL). The pupation rate for larvae reared under HL and LL was 94.5 and $89.9 \%$, respectively, and no extreme death event was observed in any 
larvae-rearing pan. Eclosed adults from each larval nutritional treatment were maintained in paperboard cages $(20.5 \mathrm{~cm}$ height $\times 18.5 \mathrm{~cm}$ diameter $)$ and randomly assigned to one of two adult nutritional regimes with different food quality: a well-nourished treatment with ad libitum access to a $10 \%$ sucrose solution, representing good adult nutrition (hereafter GA); or a malnourished treatment with ad libitum access to $1 \%$ sucrose solution, representing poor adult nutrition (hereafter PA). Hence, there are two different levels of larval and adult nutrition, respectively (Fig. 1; Additional file 1). After keeping males and females together for 3-5 days to allow for mating, mosquitoes were cold-anesthetized at $4{ }^{\circ} \mathrm{C}$ and sexed on chilled Petri dishes using a stereomicroscope (Stemi DV4, Carl Zeiss AG, Jena, Germany). Females were retained in smaller paperboard cages $(12 \mathrm{~cm}$ height $\times 11 \mathrm{~cm}$ diameter) with ad libitum access to the same adult nutritional treatments as above. Larvae and adults were kept in incubators (I-36VL, Geneva Scientific LLC, Fontana, USA) at $27( \pm 1)^{\circ} \mathrm{C}$ and $75( \pm 5) \%$ relative humidity (RH) under a 12:12 h Light (L): Dark (D) photoperiod throughout the experiments.

\section{Bioassays and life history traits}

Six-to-eight day old females were provided with access to bovine blood (Hemostat Laboratories, Dixon, USA) for $45 \mathrm{~min}$ via a Hemotek Membrane Feeding System (PS6, Hemotek Ltd., Blackburn, UK). Prior to the bloodfeeding assay, these mosquitoes had been starved for 24 $\mathrm{h}$ by depriving them of sucrose solutions. From 24 to 12 h prior to the blood-feeding assay a cotton roll soaked with DI water was provided to them. Engorged mosquitoes were separated from unfed ones on chilled petri dishes after cold-anesthesia at $4{ }^{\circ} \mathrm{C}$ for $10 \mathrm{~min}$. Fifty engorged individuals were randomly selected from each nutritional level and placed individually in small paperboard cages $(5.5 \mathrm{~cm}$ height $\times 9 \mathrm{~cm}$ diameter) for life history assays. In each cage, a strip of seed germination paper was placed along the inner wall and kept moist daily from day 2 to 7 post blood-feeding to allow for oviposition. All caged individuals were provided with ad libitum access to either a 1\% (PA) or 10\% (GA) sucrose solution until death (see Fig. 1). Mortality of mosquitoes was checked daily and longevity was recorded as the number of days from blood-feeding to death (hereafter post-blood-feeding longevity). Immediately after the death of a mosquito, all the eggs inside a cage (including germination paper and all inner surface of the cage) were counted using a stereomicroscope. The measure of fecundity we recorded was the total number of eggs counted in a cage. Dead individuals were removed and stored at $-80^{\circ} \mathrm{C}$ until their wing length could be measured, as a standard proxy for body size. Wing length was measured as the distance from the axial incision to the apical margin excluding the fringe of the scales [38]. The measurement of wing length was conducted using an inverted microscope (IX51, Olympus, Japan) and Olympus cellSens Entry 2.3 software.

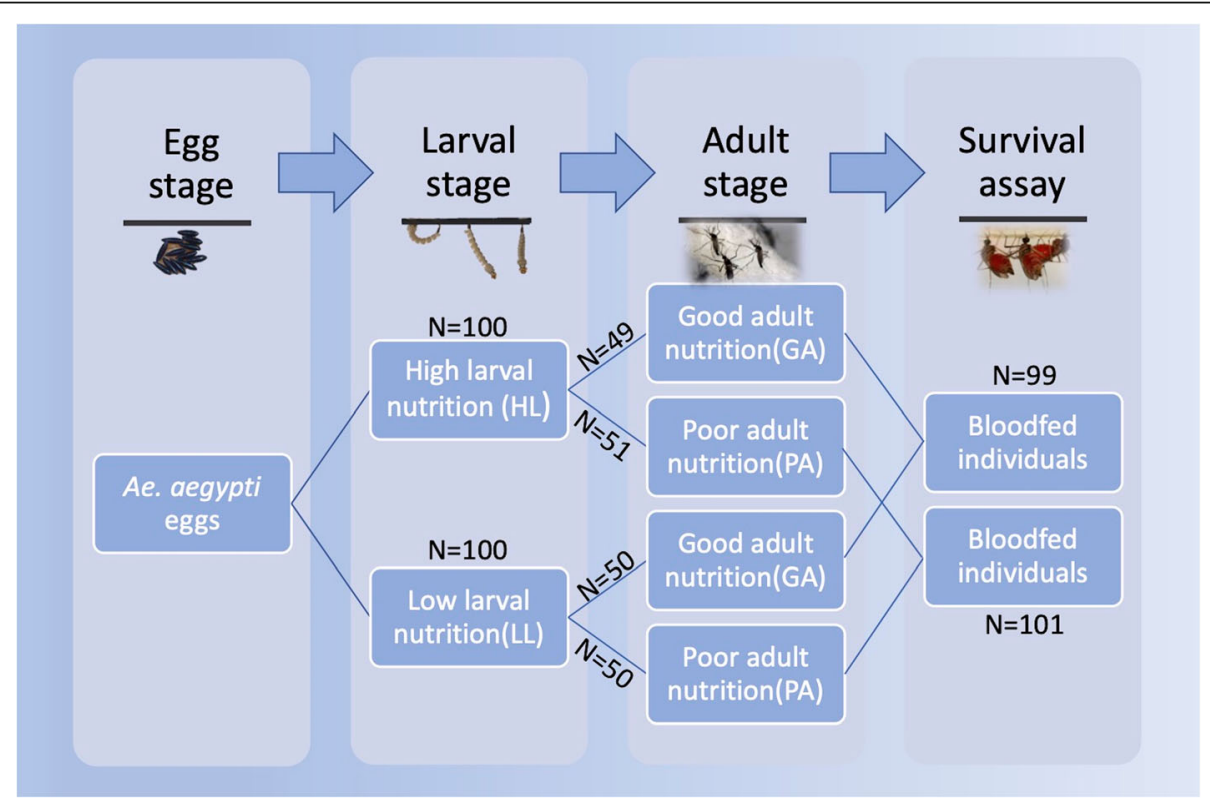

Fig. 1 The schematic diagram of experimental design. High or low larval nutrition represents an access to larval food on days 2, 4, 5, and 6 post hatching or on days 2 and 6 post hatching; Good or poor adult nutrition represents an ad libitum access to 10\% or 1\% sucrose solution daily; Females were allowed to mate and take a blood meal before the start of the survival assay 


\section{Statistical analyses}

Two-way analysis of variance (ANOVA) was conducted to detect whether there were significant differences in post blood-feeding longevity, body size and fecundity between any two levels of larval nutrition, adult nutrition and their interaction. The normality of these three variables was examined in normal quantile plots. Outliers that exceeded the range of upper or lower whiskers in Tukey's boxplots were removed before the two-way ANOVA $[39,40]$. To further assess the effects of larval and adult nutritional stress on daily survival of mosquitoes, a survival analysis was performed using the $\mathrm{R}$ packages survival [41] and survminer [42] with the KaplanMeier Method and Log-Rank Test. A Cox Proportional Hazards model $(\mathrm{CPH})$ was fitted to assess the death risk of mosquitoes reared from different levels of the treatments. We also examined potential trade-offs between life history traits by performing linear regression analyses between each pair of traits. To further test whether nutritional treatment influences the significant relationship between any two of the three life history traits from the above linear regressions, analysis of covariance (ANCOVA) was performed to compare the regression slopes of different levels of the treatments using the package car [43]. Statistical analyses were carried out in R software v. 3.6.3 [44].

\section{Results}

The mean wing length of mosquitoes from high larval nutrition (HL), low larval nutrition (LL), good adult nutrition (GA) and poor adult nutrition (PA) was $2.76 \pm$ $0.01 \mathrm{SE} \mathrm{mm}, 2.49 \pm 0.01 \mathrm{SE} \mathrm{mm}, 2.62 \pm 0.02 \mathrm{SE} \mathrm{mm}$ and $2.63 \pm 0.02$ SE mm, respectively (Table 1 ). There was significant difference between $\mathrm{HL}$ and LL (two-way ANOVA, $F_{1}, 193=336.77, p<0.001$; Fig. 2a), indicating that larval food quantity significantly affected adult size. As wing length is fixed in adults, no difference was found between adult nutritional levels (two-way

Table 1 Mean wing length, fecundity and survival of Aedes aegypti by different levels of treatment

\begin{tabular}{clll}
\hline Treatment & Wing length & Fecundity & Survival \\
\hline Larval nutrition & & & \\
HL & $2.76 \pm 0.01 \mathrm{SE}$ & $85.34 \pm 1.75 \mathrm{SE}$ & $25.47 \pm 1.61 \mathrm{SE}$ \\
$\mathrm{LL}$ & $2.49 \pm 0.01 \mathrm{SE}$ & $45.37 \pm 2.54 \mathrm{SE}$ & $28.28 \pm 1.74 \mathrm{SE}$ \\
Adult nutrition & & & \\
GA & $2.62 \pm 0.02 \mathrm{SE}$ & $73.70 \pm 2.33 \mathrm{SE}$ & $33.67 \pm 1.31 \mathrm{SE}$ \\
PA & $2.63 \pm 0.02 \mathrm{SE}$ & $57.29 \pm 3.29 \mathrm{SE}$ & $20.57 \pm 1.72 \mathrm{SE}$
\end{tabular}

Abbreviations used in the table listed as following. $H L$ high larval nutrition, $L L$ low larval nutriton, GA good adult nutrition, $P A$ poor adult nutrition, $S E$ standard error. Mean wing length is recorded to 2 decimal places in $\mathrm{mm}$ and measured as described in the main text. Mean fecundity is represented by the number of eggs laid. Mean survival is the number of days that the individual lived post-blood-feeding
ANOVA, $\mathrm{F}_{1,193}=0.09, p=0.76$; Fig. 2a). The interaction between larval and adult nutrition was not significant (two-way ANOVA, $\mathrm{F}_{1,193}=3.46, p=0.06$ ).

The mean fecundity of mosquitoes from HL, LL, GA and PA was $85.34 \pm 1.75 \mathrm{SE}, 45.37 \pm 2.54 \mathrm{SE}, 73.70 \pm 2.33$ SE and 57.29 $\pm 3.29 \mathrm{SE}$, respectively (Table 1 ). There was a significant difference between HL and LL (two-way ANOVA, $F_{1}, 182=194.25, p<0.001$; Fig. $2 b$ ), and between GA and PA (two-way ANOVA, $\mathrm{F}_{1,182}=29.43$, $p<0.001$; Fig. 2b), indicating that both the larval and adult diets affected mosquito egg-laying. However, there was no statistically significant interaction between larval and adult nutrition on fecundity (two-way ANOVA, $\mathrm{F}_{1}$, $182=2.94, p=0.08)$, suggesting that the effects of larval and adult nutrition on fecundity were additive rather than synergistic.

The mean post blood-feeding longevity of mosquitoes from HL, LL, GA and PA was $25.47 \pm 1.61 \mathrm{SE} d, 28.28 \pm$ 1.74. SE d, $33.67 \pm 1.31 \mathrm{SE} d$ and $20.57 \pm 1.72 \mathrm{SE} d$, respectively (Table 1). There was a significant difference between GA and PA (two-way ANOVA, $F_{1}, 190=36.44$, $p<0.001$; Fig. 2c), indicating that adult food quality significantly affected adult longevity. No significant effect was found between HL and LL (two-way ANOVA, $\mathrm{F}_{1}$, $190=1.67, p=0.20$; Fig. 2c) nor in larval and adult nutritional interaction (two-way ANOVA, $\mathrm{F}_{1}, 190=2.00, p=$ 0.16 ), indicating that larval food quantity did not affect adult survival. Survival curves also showed a significant difference between GA and PA (Log-rank $p<0.001$; Fig. 3) and no difference between HL and LL (Log-rank $p=0.39$; Fig. 3). The $\mathrm{CPH}$ model including larval nutrition, adult nutrition and wing length (body size) as covariates indicated that poor adult nutrition increased the death risk of mosquitoes (hazard ratio 1.64, $p<0.001$, GA as reference; Fig. 4), while the effects of larval nutrition ( $p=0.67$; Fig. 4) and body size ( $p=0.22$; Fig. 4 ) were not significant..

There was a positive correlation between fecundity and wing length (linear regression using fecundity and wing length as dependent and explanatory variable respectively: estimate $\pm \mathrm{SE}=110.18 \pm 10.04, \mathrm{t}=10.98, p<$ $0.001, R^{2}=0.38$ ). The slope of this positive relationship did not differ between two levels of larval (ANCOVA, slope $=66.79, \quad p<0.001$; Fig. 5a) or adult nutrition (ANCOVA, slope $=111.54, \quad p<0.001 ; \quad$ Fig. $5 b)$. In addition, the effects of nutritional treatments on fecundity after controlling for the effect of body size (wing length) were significant (larval nutrition: $\mathrm{F}_{2,197}=70.91$, $p<0.001, R_{2}=0.42$; adult nutrition: $\mathrm{F}_{2,197}=74.74, p<$ $0.001, R_{2}=0.43$ ). There was also a significantly positive relationship between mosquito fecundity and survival (estimate $\pm \mathrm{SE}=0.29 \pm 0.13, \mathrm{t}=2.23, p=0.027, R^{2}=$ $0.02)$, but no significant relationship was found between wing length and survival (estimate $\pm \mathrm{SE}=-0.001 \pm$ $0.001, \mathrm{t}=-1.38, p=0.17$ ). 


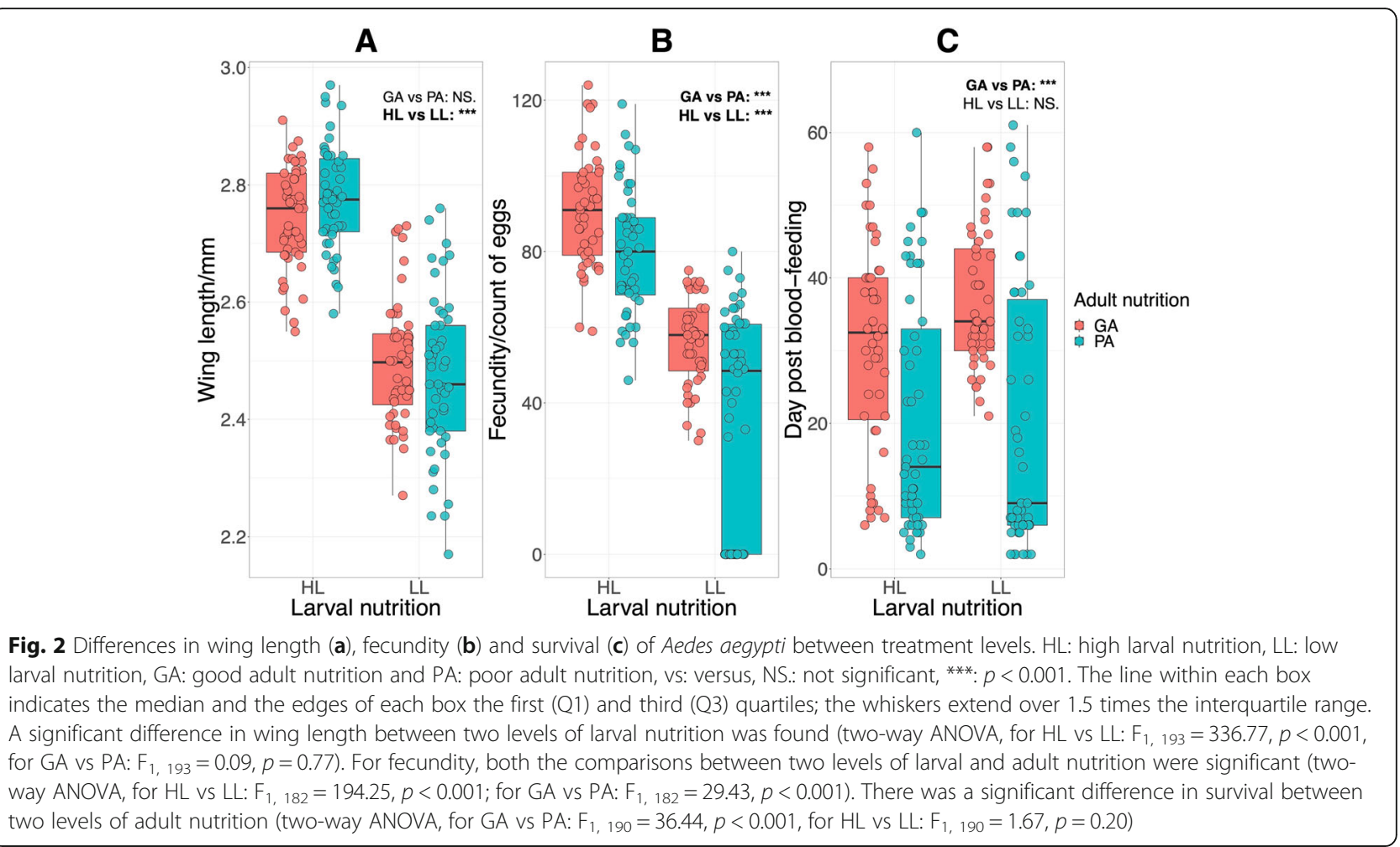

\section{Discussion}

In this study we investigated how different quantities of larval and adult nutrition affect several key life history traits of adult female Ae. aegypti mosquitoes. We found that while adult size was influenced by larval nutrition, and survival was influenced only by adult nutrition, fecundity depended on both larval and adult nutrition.
The quantity of larval nutrition affected mosquito wing length, a proxy for body size, which is consistent with previous studies [37, 45, 46]. Body size has been suggested to be an important life history trait of mosquitoes because of its close connection to or correlation with other traits that influence fitness and susceptibility to infection and dissemination [10]. In our study,
A

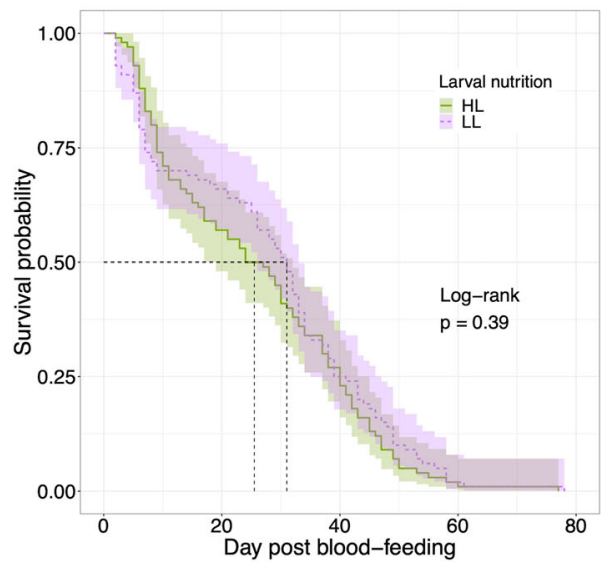

B

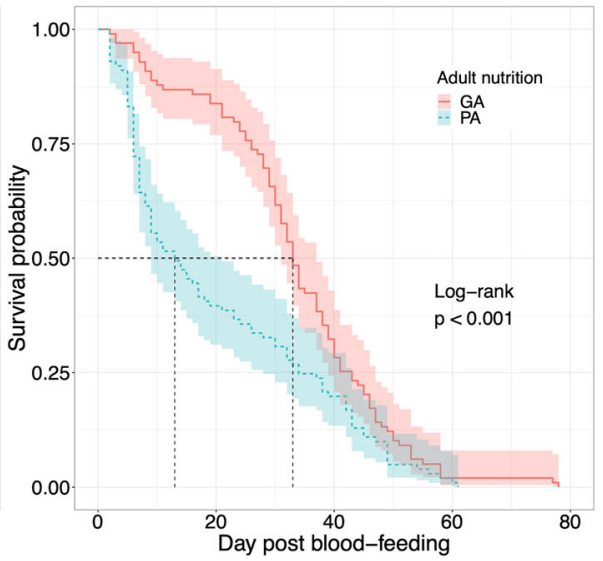

Fig. 3 Survival curves between nutritional levels of larval nutrition (a) and adult nutrition (b). Survival probabilities were estimated by KaplanMeier method and shadow areas represent 95\% confidence intervals. HL: high larval nutrition, LL: low larval nutrition, GA: good adult nutrition, PA: poor adult nutrition. The dotted line represents day at median survival for each nutritional level $(H L=25.5, L L=31.0, G A=33.0$, and $P A=13.0)$. There was a significant difference in survival probability between GA and PA (Log-rank $p<0.001$ ), while the difference between $H L$ and LL was not significant (Log-rank $p=0.39)$ 


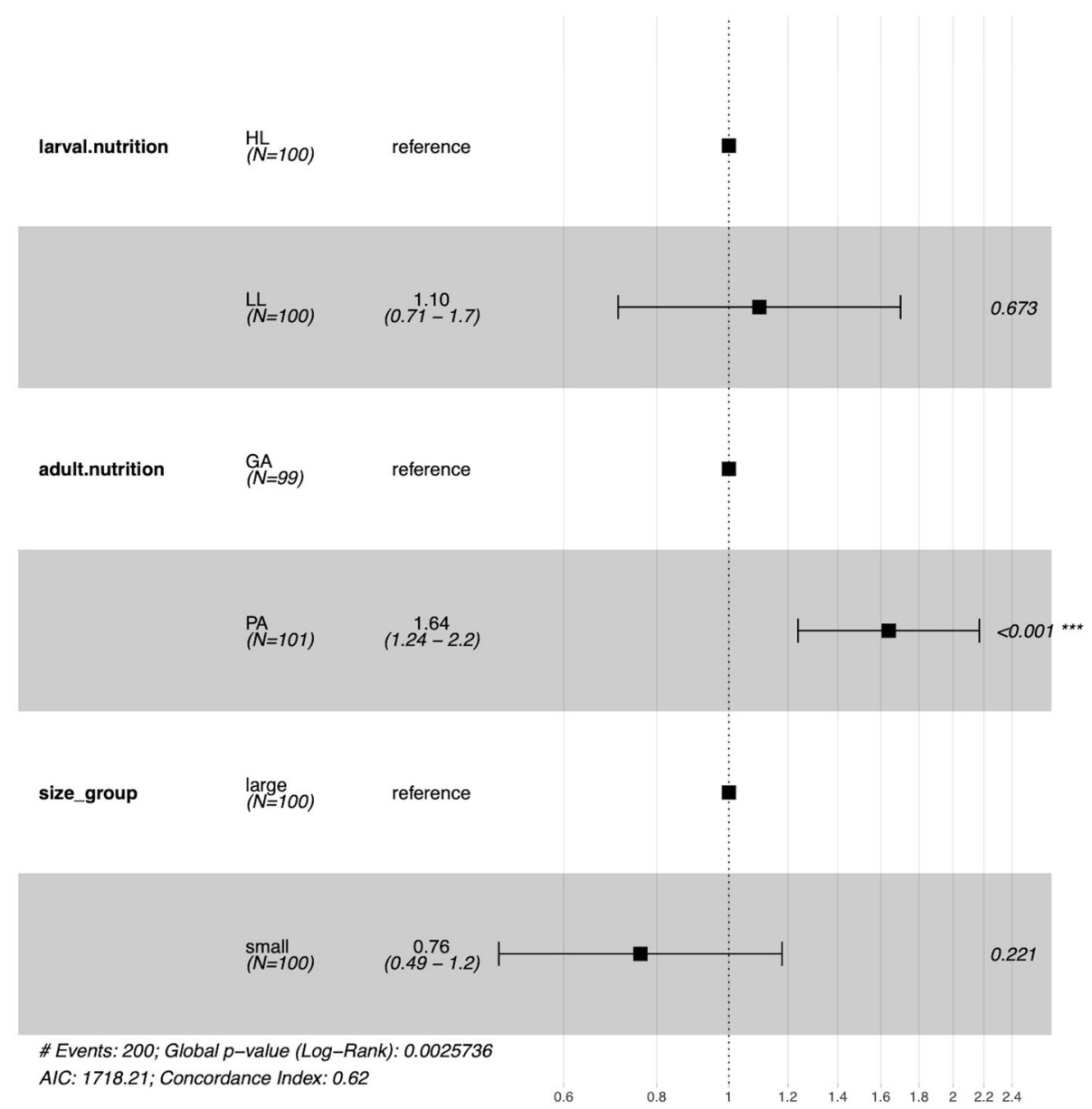

Fig. 4 Hazard ratios for mosquitoes from different nutritional levels and body size (wing length). Cox Proportional-Hazards model showed that poor adult nutrition increased the death risk of mosquitoes (hazard ratio 1.64, $p<0.001, \mathrm{GA}$ as reference), while the effects of larval nutrition ( $p=$ $0.67)$ and body size $(p=0.22)$ were not significant

however, the effect of body size was only noticeable on fecundity.

Mosquitoes feeding on a $10 \%$ sucrose solution had a significantly greater longevity than their counterparts feeding on a $1 \%$ sucrose solution, regardless of larval nutrition. Similarly, Briegel et al [47] found that higher sucrose concentrations $(0.5-50 \%)$ extend the survival time of Ae. aegypti, probably because higher concentrations allow for greater increases in energy reserves. Larval nutrition, in our case, had no significant influence on adult survivorship. A negative effect of increased larval nutrition on adult $A e$. aegypti longevity has been reported by previous studies [35]. However, larval competition for nutrition (i.e., reduced larval nutrition) can also reduce adult $A e$. aegypti longevity under certain conditions (e.g., under stress related to low humidity) [18]. Opposite effects of larval nutrition on adult longevity have thus been reported within this species. Similar contradictory results have also been reported in other mosquito species (e.g., Anopheles gambiae [45, 48]), indicating that populations of different genetic origins will likely have different life history responses to nutritional stress, though this is an area for further research. Besides differences in the genetic background of different mosquito populations used for these experiments, it is possible that the differences in outcomes between studies could be caused by the methodological diversities among studies, such as larval food quantity and quality used, as well as larval density or habitat characteristics. Some studies used fish food or liver powder-based diet as larval nutrition $[49,50]$, while others used microorganisms as the natural diet for larvae [51], which further handicaps the direct comparison of results between studies. It is also possible that effects of larval nutrition on longevity are only expressed when mosquitoes are placed in stressful conditions, though the current study suggests that low sucrose availability at least does not induce that outcome. Besides these differences in methodology, whether a female is mated or not could also mediate the effect of larval nutrition on insect lifespan. May et al [52], for 


\section{A}

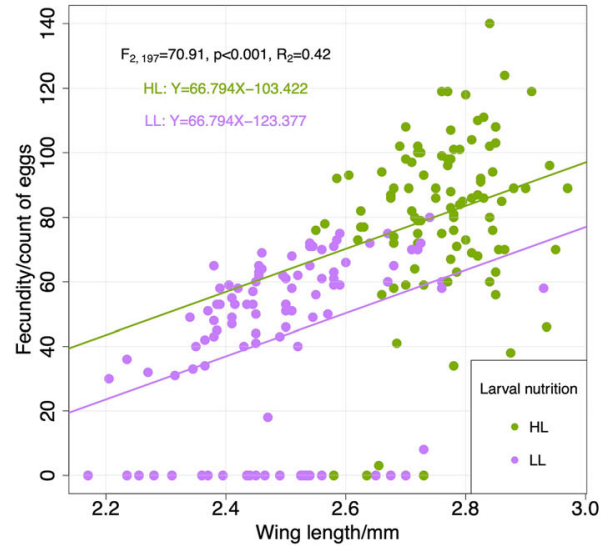

B

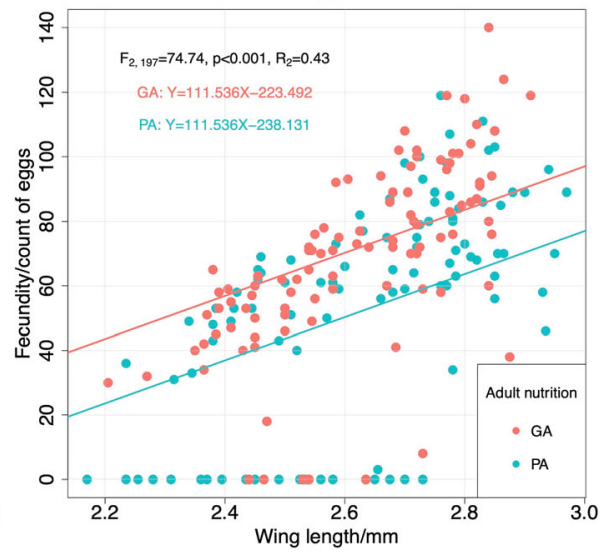

Fig. 5 Regression relationship between fecundity and wing length of mosquitoes from larval (a) and adult nutrition (b). HL: high larval nutrition, LL: low larval nutrition, GA: good adult nutrition, PA: poor adult nutrition. Analysis of covariance (ANCOVA) showed that the positive relationship between fecundity and wing length did not change at different nutritional levels of larval (slope $=66.79, p<0.001)$ or adult nutrition (slope $=$ $111.54, p<0.001$ ). The effects of nutritional treatments on fecundity after controlling for the effect of body size (wing length) were significant (larval nutrition: $F_{2,197}=70.91, p<0.001, R_{2}=0.42$; adult nutrition: $F_{2,197}=74.74, p<0.001, R_{2}=0.43$ )

example, demonstrated that virgin female Drosophila melanogaster reared on poor larval nutrition lived longer than their counterparts reared on more nutritious resources, while there was no influence of the amount of larval food level on the longevity of mated females. We did not vary the level of exposure to males in this study, but this would be an interesting avenue for further research.

Both larval and adult nutrition significantly affected mosquito fecundity. Both mosquitoes that were exposed to the high food regime as larvae and had access to a $10 \%$ sucrose solution as adults laid more eggs than those that had access to the lower levels of nutrition. This is in accordance with Vantaux et al [46] who found that adult An. coluzzii reared under low levels of larval food were significantly less fecund. With regard to adult nutrition, it is known that blood meal quantity and source can influence mosquito fecundity [35, 53-55], while intake of carbohydrates can also influence egg production [56, 57]. Energy reserves can be a more decisive factor for fecundity than protein, for example, Mostowy and Foster [58] found that egg number of Ae. aegypti does not correspond to blood meal size but instead closely associated with the level of energetic reserves at the time of bloodfeeding. Plant-sugar meals are shunted to the ventral diverticulum, or crop, which, when full can compete for space in the midgut for blood meals and thereby reduce blood meal intake and fecundity [58]. In our study, where mosquitoes were starved for 1 day before blood feeding, crops would have likely been considerably emptied [56], and the effect of adult nutrition levels on fecundity did not appear to depend on the nutritional reserves obtained during the larval stages, suggesting rather an additive effect of reserves on fecundity. Traditionally fecundity of a mosquito was measured as the total number of oviposited eggs and retained follicles [59]. However, oviposited eggs as a proxy for fecundity is also commonly used in recent studies [60-62], especially for those carried out with survival experiment, where retained follicles could likely be resorbed by mosquitoes later [63].

We did not detect any trade-offs between mosquito survival, size and fecundity. Trades-offs between life history traits of organisms have often been observed as a result of a limited resource that has to be allocated to growth, development and performance [64]. Here, we found an expected positive relationship between wing length and fecundity (i.e., larger-sized mosquitoes can lay larger egg clutches), and we found that egg numbers also depended on both larval and adult nutrition even after controlling for body size. However, we also found a positive relationship between fecundity and survival, indicating that longer-lived mosquitoes could also lay more eggs. Future work could explore whether other traits (e.g., related to immune function or metabolic detoxification [37]) do provide evidence of a trade-off in relation to mosquito nutrition.

While the individual effects of larval and adult nutrition on mosquito life history traits are well established, the underlying mechanisms for such effects are seldomly examined (but see [65]) and thus, poorly understood. In other insects such as D. melanogaster, the insulin/insulin-like growth factor signaling pathway has been regarded as a sensor of the insect's nutritional status and a regulator of lifespan and reproduction [66-69]. Future effort could focus on this pathway in order to reveal the 
mechanism underlying the effect of nutrition on mosquito longevity and fecundity.

\section{Conclusions}

In conclusion, mosquito larval and adult nutrition may have differential effects on their life history traits. While larval food quantity and adult food quality influence body size and survival respectively, both quantity and quality jointly affect mosquito fecundity. This has potentially important ramifications for our understanding of population dynamics and vectorial capacity of mosquitoes, in that both larval and adult environments should be considered when tracking factors influencing mosquito fitness and performance.

\section{Supplementary Information}

The online version contains supplementary material available at https://doi. org/10.1186/s12983-021-00395-z.

Additional file 1 Wing length, fecundity and survival of Aedes aegypti reared at different nutritional levels. Abbreviations used in the table listed as following. ID: mosquito identity, HL: high larval nutrition, LL: low larval nutrition, GA: good adult nutrition, PA: poor adult nutrition. Wing length is recorded to 3 decimal places in $\mathrm{mm}$ and measured as described in the main text. Fecundity is represented by the number of eggs laid. Survival is the number of days that the individual lived post-blood-feeding.

\section{Acknowledgements}

We thank the three anonymous reviewers for their careful reading of the manuscript and their insightful comments. Thanks to Seth Yates, Morgan Race and Kristof S. Gutowski for their assistance in mosquito cage crafting, wing dissections and measurements.

\section{Authors' contributions}

JY and CMS conceived and designed the study. JY and RK carried out the experiments. JY and CMS performed the statistical analyses. JY drafted the first manuscript and all authors contributed to interpretation of the data, read and approved the final manuscript.

\section{Funding}

This work was supported by the State of Illinois Used Tire Management and Emergency Public Health funds.

\section{Availability of data and materials}

All data generated or analyzed during this study are included in this published article and its supplementary information files.

\section{Declarations}

Ethics approval and consent to participate

Not applicable.

\section{Consent for publication}

Not applicable.

\section{Competing interests}

The authors declare that they have no competing interests.

Received: 17 August 2020 Accepted: 28 February 2021

Published online: 09 March 2021

\section{References}

1. Christophers SR. Aedes aegypti (L.) the yellow fever mosquito: its life history, bionomics and structure. New York: Cambridge University Press; 1960.
2. Guzman MG, Halstead SB, Artsob H, Buchy P, Farrar J, Gubler DJ, et al. Dengue: a continuing global threat. Nat Rev Microbiol. 2010;8(12):S7-S16.

3. Monath TP. Yellow fever: an update. Lancet Infect Dis. 2001;1(1):11-20.

4. Pialoux G, Gaüzère B-A, Jauréguiberry $S$, Strobel M. Chikungunya, an epidemic arbovirosis. Lancet Infect Dis. 2007;7(5):319-27.

5. Petersen $L R$, Jamieson DJ, Powers AM, Honein MA. Zika virus. N Engl J Med. 2016;374(16):1552-63.

6. Bhatt S, Gething PW, Brady OJ, Messina JP, Farlow AW, Moyes CL, et al. The global distribution and burden of dengue. Nature. 2013;496(7446):504-7.

7. Weaver SC, Charlier C, Vasilakis N, Lecuit M. Zika, chikungunya, and other emerging vector-borne viral diseases. Annu Rev Med. 2018;69:395-408.

8. Dye C. Vectorial capacity: must we measure all its components? Parasitol Today. 1986;2(8):203-9.

9. Kramer LD, Ciota AT. Dissecting vectorial capacity for mosquito-borne viruses. Curr Opin Virol. 2015:15:112-8.

10. Garrett-Jones C, Shidrawi G. Malaria vectorial capacity of a population of Anopheles gambiae: an exercise in epidemiological entomology. Bull World Health Organ. 1969;40(4):531

11. Alto BW, Reiskind MH, Lounibos LP. Size alters susceptibility of vectors to dengue virus infection and dissemination. Am J Trop Med Hygiene. 2008; 79(5):688-95.

12. Dye $\mathrm{C}$. The analysis of parasite transmission by bloodsucking insects. Annu Rev Entomol. 1992:37(1):1-19.

13. Clements AN. The biology of mosquitoes: development, nutrition and reproduction, vol. 1: Chapman \& Hall London; 1992.

14. Westby KM, Juliano SA. The roles of history: age and prior exploitation in aquatic container habitats have immediate and carry-over effects on mosquito life history. Ecol Entomol. 2017;42(6):704-11.

15. Dickson LB, Jiolle D, Minard G, Moltini-Conclois I, Volant S, Ghozlane A, et al. Carryover effects of larval exposure to different environmental bacteria drive adult trait variation in a mosquito vector. Sci Adv. 2017;8:e1700585.

16. Hawley $\mathbf{W}$. The effect of larval density on adult longevity of a mosquito, Aedes sierrensis: epidemiological consequences. J Anim Ecol. 1985;1:955-64.

17. Ciota AT, Matacchiero AC, Kilpatrick AM, Kramer LD. The effect of temperature on life history traits of Culex mosquitoes. J Med Entomol. 2014; 51(1):55-62.

18. Reiskind $M$, Lounibos $L$. Effects of intraspecific larval competition on adult longevity in the mosquitoes Aedes aegypti and Aedes albopictus. Med Vet Entomol. 2009;23(1):62-8.

19. Alto BW, Lounibos LP, Mores $C N$, Reiskind MH. Larval competition alters susceptibility of adult Aedes mosquitoes to dengue infection. Proc R Soc B Biol Sci. 2008;275(1633):463-71.

20. Shapiro LL, Murdock CC, Jacobs GR, Thomas RJ, Thomas MB. Larval food quantity affects the capacity of adult mosquitoes to transmit human malaria. Proc Royal Soc Biol Sci. 2016;283(1834):20160298.

21. Costa EA, Santos EM, Correia JC, Albuquerque CM. Impact of small variations in temperature and humidity on the reproductive activity and survival of Aedes aegypti (Diptera, Culicidae). Revista Brasileira de Entomologia. 2010; 54(3):488-93.

22. Thu HM, Aye KM, Thein S. The effect of temperature and humidity on dengue virus propagation in Aedes aegypti mosquitos. Southeast Asian Trop Med Public Health. 1998;29(2):280-4.

23. Nasci RS. Influence of larval and adult nutrition on biting persistence in Aedes aegypti (Diptera: Culicidae). J Med Entomol. 1991;28(4):522-6.

24. Merritt R, Dadd R, Walker E. Feeding behavior, natural food, and nutritional relationships of larval mosquitoes. Annu Rev Entomol. 1992;37(1):349-74.

25. Washburn J. Regulatory factors affecting larval mosquito populations in container and pool habitats: implications for biological control. J Am Mosq Control Assoc. 1995;11(2):279-83.

26. Edman JD, Strickman D, Kittayapong P, Scott TW. Female Aedes aegypti (Diptera: Culicidae) in Thailand rarely feed on sugar. J Med Entomol. 1992; 29(6):1035-8.

27. Scott TW, Naksathit A, Day JF, Kittayapong P, Edman JD. A fitness advantage for Aedes aegypti and the viruses it transmits when females feed only on human blood. Am J Trop Med Hygiene. 1997;57(2):235-9.

28. Harrington LC, Edman JD, Scott TW. Why do female Aedes aegypti (Diptera: Culicidae) feed preferentially and frequently on human blood? J Med Entomol. 2001:38(3):411-22.

29. Martinez-Ibarra JA, Rodriguez MH, Arredondo-Jimenez JI, Yuval B. Influence of plant abundance on nectar feeding by Aedes aegypti (Diptera: Culicidae) in southern Mexico. J Med Entomol. 1997;34(6):589-93. 
30. Sissoko F, Junnila A, Traore MM, Traore SF, Doumbia S, Dembele SM, et al. Frequent sugar feeding behavior by Aedes aegypti in Bamako, Mali makes them ideal candidates for control with attractive toxic sugar baits (ATSB). PLoS One. 2019;14:6.

31. Olson MF, Garcia-Luna S, Juarez JG, Martin E, Harrington LC, Eubanks MD, et al. Sugar feeding patterns for Aedes aegypti and Culex quinquefasciatus (Diptera: Culicidae) mosquitoes in South Texas. J Med Entomol. 2020;57: 1111-9.

32. Scott-Fiorenzano JM, Fulcher AP, Seeger KE, Allan SA, Kline DL, Koehler PG, et al. Evaluations of dual attractant toxic sugar baits for surveillance and control of Aedes aegypti and Aedes albopictus in Florida. Parasites Vectors. 2017;10(1):9

33. Fikrig K, Johnson BJ, Fish D, Ritchie SA. Assessment of synthetic floral-based attractants and sugar baits to capture male and female Aedes aegypti (Diptera: Culicidae). Parasites Vectors. 2017;10(1):32

34. Lalubin F, Deledevant A, Glaizot O, Christe P. Natural malaria infection reduces starvation resistance of nutritionally stressed mosquitoes. J Anim Ecol. 2014:83(4):850-7.

35. Joy TK, Arik AJ, Corby-Harris V, Johnson AA, Riehle MA. The impact of larval and adult dietary restriction on lifespan, reproduction and growth in the mosquito Aedes aegypti. Exp Gerontol. 2010;45(9):685-90.

36. Alto BW, Lounibos LP, Higgs S, Juliano SA. Larval competition differentially affects arbovirus infection in Aedes mosquitoes. Ecology. 2005;86(12):327988 .

37. Telang A, Qayum A, Parker A, Sacchetta B, Byrnes G. Larval nutritional stress affects vector immune traits in adult yellow fever mosquito Aedes aegypti (Stegomyia aegypti). Med Vet Entomol. 2012;26(3):271-81.

38. Nasci RS. Relationship of wing length to adult dry weight in several mosquito species (Diptera: Culicidae). J Med Entomol. 1990;27(4):716-9.

39. Tukey JW. Exploratory data analysis. Reading: Addison-Wesley; 1977.

40. Rousseeuw PJ, Hubert M. Robust statistics for outlier detection. Wiley Interdisc Rev. 2011;1(1):73-9.

41. Therneau T. A Package for Survival Analysis in S. version 2.38; 2015.

42. Kassambara A, Kosinski M, Biecek P, Fabian S. Package 'survminer'. Drawing Survival Curves using 'ggplot2'(R package version 03 1); 2017.

43. Fox J, Weisberg S, Adler D, Bates D, Baud-Bovy G, Ellison S, et al. Package "car": Companion to applied regression. Computer software package at, https://cran r-project org/web/packages/car/index html. 2018.

44. R Core Team. R: A language and environment for statistical computing. Vienna: R Foundation for Statistical Computing; 2017

45. Takken W, Smallegange RC, Vigneau AJ, Johnston V, Brown M, MordueLuntz AJ, et al. Larval nutrition differentially affects adult fitness and Plasmodium development in the malaria vectors Anopheles gambiae and Anopheles stephensi. Parasites Vectors. 2013:6(1):345.

46. Vantaux A, Lefèvre T, Cohuet A, Dabiré KR, Roche B, Roux O. Larval nutritional stress affects vector life history traits and human malaria transmission. Sci Rep. 2016;6(1):1-10.

47. Briegel H, Knusel I, Timmermann SE. Aedes aegypti: size, reserves, survival, and flight potential. J Vect Ecol. 2001;26:21-31.

48. Vantaux A, Ouattarra I, Lefèvre T, Dabiré KR. Effects of larvicidal and larval nutritional stresses on Anopheles gambiae development, survival and competence for Plasmodium falciparum. Parasites Vectors. 2016;9(1):226.

49. Couret J, Dotson E, Benedict MQ. Temperature, larval diet, and density effects on development rate and survival of Aedes aegypti (Diptera: Culicidae). PloS One. 2014;9(2):e87468.

50. Benedict MQ, Hunt CM, Vella MG, Gonzalez KM, Dotson EM, Collins CM. Pragmatic selection of larval mosquito diets for insectary rearing of Anopheles gambiae and Aedes aegypti. Plos One. 2020;15(3):e0221838.

51. Souza RS, Virginio F, Riback TIS, Suesdek L, Barufi JB, Genta FA. Microorganism-based larval diets affect mosquito development, size and nutritional reserves in the yellow fever mosquito Aedes aegypti (Diptera: Culicidae). Front Physiol. 2019;10:152.

52. May CM, Doroszuk A, Zwaan BJ. The effect of developmental nutrition on life span and fecundity depends on the adult reproductive environment in Drosophila melanogaster. Ecol Evol. 2015;5(6):1156-68.

53. Bennett GF. The influence of the blood meal type on the fecundity of Aedes (Stegomyia) aegypti L.(Diptera: Culicidae). Can J Zool. 1970;48(3):539-43.

54. Damiens D, Soliban S, Balestrino F, Alsir R, Vreysen M, Gilles J. Different blood and sugar feeding regimes affect the productivity of Anopheles arabiensis colonies (Diptera: Culicidae). J Med Entomol. 2013;50(2):336-43.
55. Richards SL, Anderson SL, Yost SA. Effects of blood meal source on the reproduction of Culex pipiens quinquefasciatus (Diptera: Culicidae). J Vect Ecol. 2012;37(1):1-7.

56. Foster WA. Mosquito sugar feeding and reproductive energetics. Annu Rev Entomol. 1995;40(1):443-74.

57. Gary RE Jr, Foster WA. Effects of available sugar on the reproductive fitness and vectorial capacity of the malaria vector Anopheles gambiae (Diptera: Culicidae). J Med Entomol. 2001;38(1):22-8.

58. Mostowy WM, Foster WA. Antagonistic effects of energy status on meal size and egg-batch size of Aedes aegypti (Diptera: Culicidae). J Vect Ecol. 2004;29: 84-93.

59. Leisnham PT, Sala L, Juliano SA. Geographic variation in adult survival and reproductive tactics of the mosquito Aedes albopictus. J Med Entomol. 2014; 45(2):210-21.

60. Gendrin M, Rodgers FH, Yerbanga RS, Ouédraogo JB, Basáñez M-G, Cohuet $A$, et al. Antibiotics in ingested human blood affect the mosquito microbiota and capacity to transmit malaria. Nat Commun. 2015;6(1):1-7.

61. Delhaye J, Aletti C, Glaizot O, Christe P. Exposure of the mosquito vector Culex pipiens to the malaria parasite Plasmodium relictum: effect of infected blood intake on immune and antioxidant defences, fecundity and survival. Parasites Vectors. 2016;9(1):616.

62. Hauser G, Thiévent K, Koella JC. The ability of Anopheles gambiae mosquitoes to bite through a permethrin-treated net and the consequences for their fitness. Sci Rep. 2019;9(1):1-8.

63. Clifton ME, Noriega FG. The fate of follicles after a blood meal is dependent on previtellogenic nutrition and juvenile hormone in Aedes aegypti. J Insect Physiol. 2012;58(7):1007-19.

64. Van Noordwijk AJ, de Jong G. Acquisition and allocation of resources: their influence on variation in life history tactics. Am Nat. 1986;128(1):137-42.

65. Pooraiiouby R, Sharma A, Beard J, Reyes J, Nuss A, Gulia-Nuss M. Nutritional quality during development alters insulin-Like peptides' expression and physiology of the adult yellow fever mosquito, Aedes aegypti. Insects. 2018; 9(3): 110.

66. Giannakou ME, Partridge L. Role of insulin-like signalling in Drosophila lifespan. Trends Biochem Sci. 2007;32(4):180-8.

67. Morris SNS, Coogan C, Chamseddin K, Fernandez-Kim SO, Kolli S, Keller JN et al. Development of diet-induced insulin resistance in adult Drosophila melanogaster. Biochim Biophys Acta. 2012;1822(8):1230-7.

68. Badisco L, Van Wielendaele P, Vanden BJ. Eat to reproduce: a key role for the insulin signaling pathway in adult insects. Front Physiol. 2013;4:202.

69. Altintas O, Park S, Lee SJ. The role of insulin/IGF-1 signaling in the longevity of model invertebrates, C. elegans and D. melanogaster. BMB Rep. 2016;49(2):81.

\section{Publisher's Note}

Springer Nature remains neutral with regard to jurisdictional claims in published maps and institutional affiliations.

\section{Ready to submit your research? Choose BMC and benefit from:}

- fast, convenient online submission

- thorough peer review by experienced researchers in your field

- rapid publication on acceptance

- support for research data, including large and complex data types

- gold Open Access which fosters wider collaboration and increased citations

- maximum visibility for your research: over $100 \mathrm{M}$ website views per year

At $\mathrm{BMC}$, research is always in progress.

Learn more biomedcentral.com/submission 